\title{
4. The mixed background of the migrant groups
}

The 14 groups we study have the common denominator that they have left a country of origin and resettled in a social-democratic welfare regime. On most other parameters they vary. They vary in the composition of gender, length of stay in Denmark, reasons for migrating, naturalization, current family constellation, educational background, labour market attachment, and religious beliefs. Thus, if such factors are believed to scape migrants' assimilation, in general, or welfare attitudes specifically, one could expect sizeable variation across migrant groups. This chapter describes the variation in background variables of the 14 different groups, which contributes to the overall most-different design logic of the book. Furthermore, the chapter gives a first contextual insight into the 14 migrant groups' socio-economic position in Denmark. The descriptions are based on those migrants who answered our survey; using weighted data to provide descriptions that are close to being representative of the 14 different groups.

\section{THE DIFFERENT LENGTHS OF TIME SINCE THE FIRST SETTLEMENT IN DENMARK}

Time in the destination countries is often considered the main driver of assimilation, as discussed in Chapter 2. Figure 4.1 shows the first time the Mifare migrants were registered with permanent settlement in Denmark. The interviewed migrants from Turkey have arrived from the 1970s onwards. The median number of years since first registration in Denmark is 21 years. Thereby the migrants from Turkey are the group with the longest attachment to Denmark, on average. The migrants from Great Britain (GBR) have also arrived steadily since the mid-1970s. The median number of years in Denmark is 16 years. However, the most common is to be registered in Denmark in 2014. Seven per cent of migrants from Great Britain were registered for the first time in 2014. The migrants from the United Stated (USA) have also been connected to Denmark for a long time, on average. The median number of years since the first registered settlement is 11 years. However, 10 per cent were registered in 2014, which again is the most common registration year. In contrast, the migrants from Romania, Spain, and Poland primarily entered 
Denmark within the last five years. The median numbers of years since first registration is respectively four, five, and seven years. The migrants from Japan, China, the Philippines, and Russia are somewhere in-between the early and later arrivers. Unfortunately, the Danish registers do not provide historical information on the type of entrance. However, as all Mifare-origin countries are stable, close to none of these migrants came as forced migrants applying for asylum. Instead, it is a mix of work-migration, family reunification, and a minor group of students (see description of employment situation below).

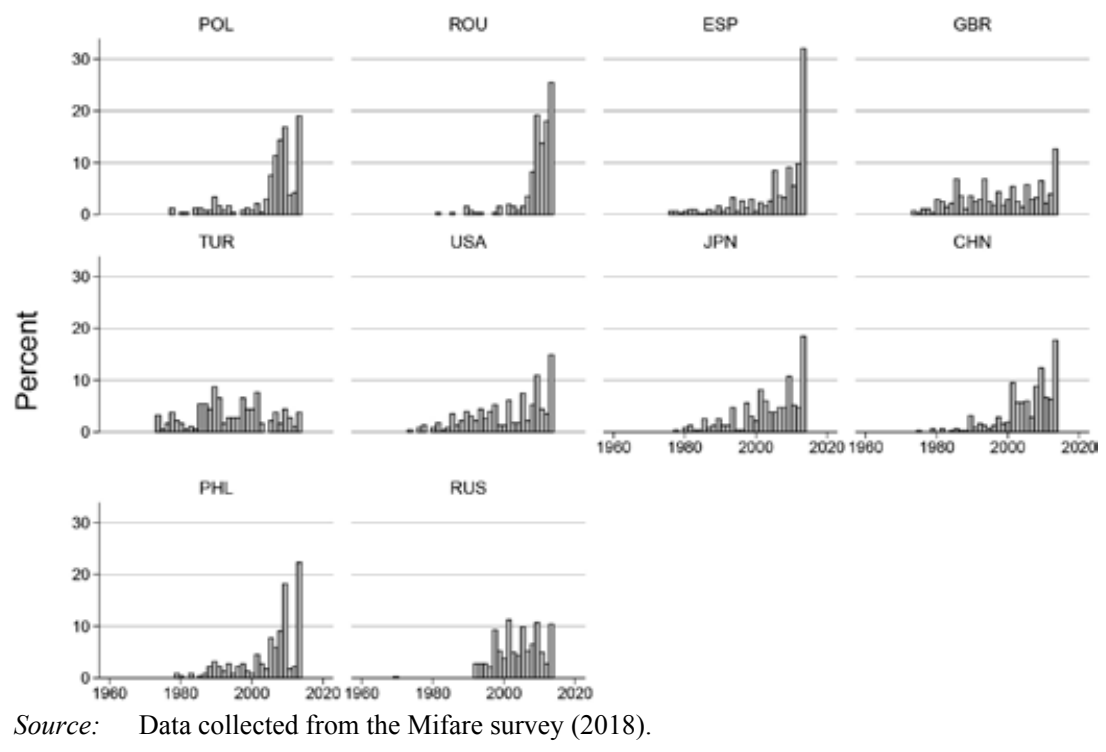

Figure 4.1 The first year of registered settlement in Denmark. Mifare migrants

The Comcon migrants came from more unstable countries and larger groups have experienced forced migration. Especially, the migrants from ex-Yugoslavia, Iraq, and Lebanon arrived in a few concentrated periods, see Figure 4.2. Most of the interviewed migrants from ex-Yugoslavia were forced to leave due to the civil war in the mid-1990s. Thus, half of the interviewed were registered in Denmark in 1995. Thus, the median number of years in Denmark is 19. The migrants from Iraq started to arrive in the mid-1980s, as a result of the Iran-Iraq war, but peaked around 2001, as a result of the fall of the Saddam regime. The median number of years for this group is 15 . The migrants from Lebanon are primarily stateless Palestinians fleeing from the 
civil wars in Lebanon in the 1980s. The median number of years in Denmark for this group is 25. Finally, the Comcon migrants from Pakistan and Turkey arrived steadily from the beginning of the 1970s onwards. The median number of years for both groups is 24 years. In the Comcon-data, migrants were asked in the survey with what status they entered Denmark. The most common answer for migrants from ex-Yugoslavia, Iraq, and Lebanon was that they came as refugees; respectively 75 per cent, 55 per cent, and 59 per cent. The second most common answer was that they came through family unification; respectively 15 per cent, 44 per cent, and 35 per cent. For the interviewed migrants from Turkey and Pakistan, the dominant answer was that they came through family unification; respectively 77 per cent and 74 per cent. The second most common answer was that they came to work or study; respectively 19 and 16 per cent.

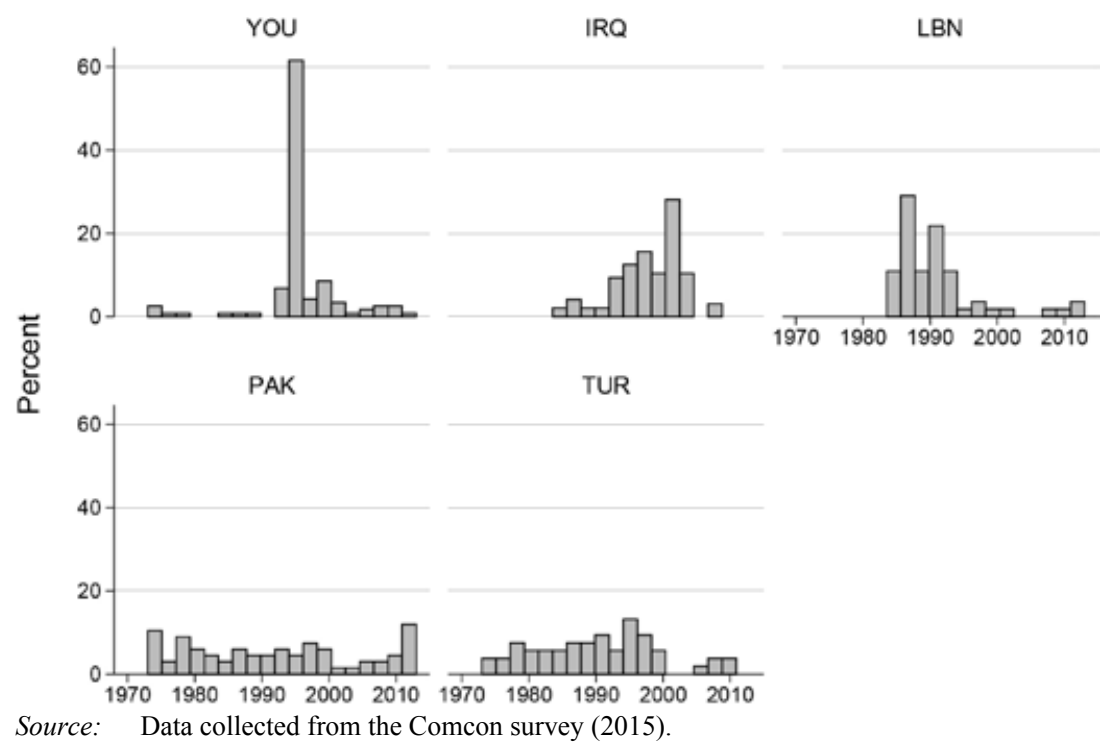

Figure 4.2 The first year of registered settlement in Denmark. Comcon migrants

One of the general trends in the Western European countries is that the migration flows have both increased in size and become more diverse, as discussed in Chapter 1. This trend is represented in our data. In terms of length since the first registration, the figures demonstrate a considerable variation across the groups. The work-migrants from Poland, Romania, and Spain have 
been in Denmark for a relatively short time. The work-migrants from Turkey and Pakistan have been in Denmark for a much longer time and many of the interviewed have entered through family unification with the guest workers of the 1960s and 1970s or their descendants. The migrants from ex-Yugoslavia, Iraq, and Lebanon have been in Denmark since the wars in the origin country. Finally, there are less well-known groups of short-, medium-, and long-term migrants from Great Britain, the US, Japan, China, the Philippines, and Russia.

\section{THE DIFFERENT NATURALIZATION}

From a narrow state perspective, formal citizenship is what distinguishes "the foreign" from "the natives". Those with citizenship are typically recognized as equal residents of the state. Thereby the naturalized enjoy the civil, political, and social rights of the state. At the same time, accepting citizenship is also a leap of faith for the migrant as the protection of the origin country is reduced, if not fully abandoned. Thus, naturalization both has a demand-side, the readiness of migrants to become formal citizens, and a supply-side, the readiness of the destination society to grant formal citizenship. Denmark has gradually tightened access to citizenship and is currently one of the most restrictive countries in Europe (Jensen, Fernández, \& Brochmann, 2017). Thus, as the migrant groups arrived at different points in time, it is therefore difficult to use formal citizenship as a valid indicator for broader assimilation. Nevertheless, the differences are displayed in Table 4.1.

In the Mifare-data, close to none of the migrants from Spain (1 per cent), Japan ( 1 per cent), US ( 2 per cent), Great Britain ( 3 per cent), Romania ( 3 per cent), and Poland (4 per cent) hold Danish citizenship. Among the migrants from China (10 per cent), Russia (13 per cent), and the Philippines (14 per cent), it is around one out of ten that hold Danish citizenship. It is only among the respondents from Turkey that one finds a sizeable group holding Danish citizenship. The share is 22 per cent in the Mifare-data. The share with Danish citizenship is larger in the Comcon-data. Stateless Palestinians from Lebanon are a special case as Denmark has signed the United Nations (UN) conventions on statelessness. Thereby these refugees had a right to immediate access to Danish citizenship. This is reflected in the data: 72 per cent hold Danish citizenship. The other groups of primarily forced migrants, those from ex-Yugoslavia and Iraq, also have a relatively high share with Danish citizenship; respectively 43 and 47 per cent. Finally, 35 per cent of the migrants from Turkey and 36 per cent of migrants from Pakistan hold Danish citizenship. Thus, there is a sizeable difference between the migrants from Turkey respectively interviewed within the Mifare- and Comcon-data, which is probably caused by differences in sampling (see Chapter 3 ). Besides constant changes in the rules for naturalization, the differences are likely to reflect the incentives 
Table 4.1 Percentage with Danish citizenship

\begin{tabular}{|c|c|c|c|c|c|c|c|c|c|c|c|c|c|c|c|}
\hline & \multicolumn{10}{|c|}{ MIFARE } & \multicolumn{5}{|c|}{ COMCON } \\
\hline & ESP & JPN & USA & GBR & ROU & POL & $\mathrm{CHN}$ & RUS & PHL & TUR & TUR & PAK & YOU & IRQ & LBN \\
\hline & 1 & 1 & 2 & 3 & 3 & 4 & 10 & 13 & 14 & 22 & 35 & 36 & 43 & 47 & 72 \\
\hline $\mathrm{N}$ & 306 & 233 & 229 & 279 & 255 & 237 & 316 & 365 & 220 & 184 & 61 & 67 & 119 & 97 & 55 \\
\hline
\end{tabular}

Source: Data collected from the Mifare survey (2018) and Comcon survey (2015).

of the different groups of migrants. Migrants from unstable origin-states, or even dissolved origin-states, have a clear incentive to seek citizenship in the destination country. Migrants from stable origin-states have fewer incentives; especially in the case of European Union (EU) migrants, where many civil and social rights are secured by EU treaties (Pennings \& Seeleib-Kaiser, 2018). Nevertheless, most importantly, we got variation across the groups.

\section{THE DIFFERENT GENDER AND FAMILY COMPOSITION}

It is a well-known fact that migrant flows are gendered in several different ways. The gender distribution could also be of importance as it is a standard finding among natives that females are more in favour of the welfare state than are males, especially so in the Nordic countries. Whether women and men assimilate differently is less clear. However, in the case of marriage-migration, which is probably more pronounced among female than male migrants, one could expect larger contact between natives and migrants. The gender distribution and household constellation in the Danish household are displayed in Table 4.2.

It is only among the migrants from Great Britain (71 per cent), Lebanon (63 per cent), and Pakistan (63 per cent) that males constitute the largest share. Females constitute the largest share of the interviewed migrants from the Philippines (91 per cent), Russia (82 per cent), and Japan (78 per cent). The gender differences go together with differences in the family constellation for households in Denmark. Starting with the male-dominated groups, the most typical for the migrants from Great Britain is to live in ethnically mixed couples in Denmark (54 per cent). This is the largest share found in all of the 14 groups. The pattern is very different for migrants from Lebanon and Pakistan. The most typical for these somewhat male-dominated groups is to live in same-origin couples in Denmark; respectively 57 and 63 per cent. Thus, around six out of ten are married or cohabit with a person from the same country of origin living in Denmark. None of the interviewed migrants from Lebanon lived in ethnically mixed couples. The figure is 7 per cent for 
Table 4.2 Gender distribution and current family constellation in the household in Denmark ${ }^{1}$ (per cent)

\begin{tabular}{|c|c|c|c|c|c|c|}
\hline & Male & Female & Single & Same-origin couple & Mixed couple & $\mathrm{N}$ \\
\hline DNK(Mifare) & 42 & 58 & 36 & 60 & 5 & 232 \\
\hline POL & 40 & 60 & 50 & 37 & 13 & 237 \\
\hline ROU & 49 & 51 & 53 & 39 & 8 & 255 \\
\hline ESP & 53 & 47 & 58 & 16 & 25 & 306 \\
\hline GBR & 71 & 29 & 34 & 13 & 54 & 279 \\
\hline TUR & 46 & 54 & 18 & 72 & 10 & 184 \\
\hline USA & 47 & 53 & 42 & 9 & 49 & 229 \\
\hline JPN & 22 & 78 & 52 & 6 & 43 & 233 \\
\hline $\mathrm{CHN}$ & 36 & 64 & 40 & 37 & 23 & 316 \\
\hline PHL & 9 & 91 & 42 & 10 & 48 & 220 \\
\hline RUS & 19 & 82 & 38 & 22 & 40 & 365 \\
\hline DNK(Comcon) & 50 & 50 & 37 & 61 & 17 & 809 \\
\hline YOU & 55 & 45 & 34 & 55 & 11 & 119 \\
\hline IRQ & 52 & 48 & 49 & 51 & 0 & 97 \\
\hline LBN & 63 & 37 & 33 & 57 & 0 & 55 \\
\hline PAK & 63 & 37 & 30 & 63 & 7 & 67 \\
\hline TUR & 50 & 50 & 21 & 72 & 4 & 61 \\
\hline
\end{tabular}

Note: $\quad{ }^{1}$ Based on Denmark Statistics classifications. Couples include cohabitation.

Origin-country family situation not included, i.e. single means living alone in a household in Denmark.

Source: Data collected from the Mifare survey (2018) and Comcon survey (2015).

the interviewed migrants from Pakistan. For the female-dominated groups, there is a tendency to live in mixed couples. Of the interviewed migrants from the Philippines, Russia, and Japan respectively 48, 40, and 43 per cent live in mixed couples. Thus, there is a pattern of Danish men living together with females from these countries of origin. These patterns of cohabitation across ethnic groups could potentially influence assimilation processes. Thus, again, the most-different design logic is underpinned by our data.

\section{THE DIFFERENT LEVELS OF EDUCATION}

The level of education is notoriously difficult to compare across countries. Migrants constitute a particularly difficult group as they might have education from the country of origin, the country of destination, and from other third or fourth countries. Therefore, it is very difficult to compare educational levels 
across migrant groups and across natives and migrants. In Chapter 5, we will describe differences in registered wage levels, which probably is a more valid indicator of human skills than are indicators of education levels. Nevertheless, there is a clear non-economic side to education, which influences norms and values. In the Nordic countries higher education tends to go together with larger support for the welfare state; especially if one controls the opposite effect of higher income. Therefore, we have established a rough measure of the highest level of education based on the international ISCED classification system. The Mifare survey asked specifically about education in the country of origin (in origin country terms) and Denmark. The Comcon survey only asked about education level in general. Due to measurement problems, we use a basic distinction between those having basic primary and lower secondary education (available in close to all countries), those having more education, but not a university degree, and finally those having a university degree (also available in close to all countries). In the ISCED terminology the three categories are lower secondary (or below), higher secondary/post-secondary, and tertiary education. Though tertiary education is available in close to all countries, it is well-known that the content varies. The Danish system follows a German tradition where university degrees are restricted to academic disciplines at centralized universities, whereas many other countries have a broader definition of university degrees, often carrying the label of "college". Despite all these pitfalls, the distributions in educational levels are shown in Table 4.3.

As for the groups having no or only very basic schooling, the interviewed migrants from Turkey, Lebanon, and Iraq stand out. In the Mifare-data, 38 per cent of the migrants from Turkey have no or only basic schooling. In the Comcon-data, the share is 42 per cent. The share among migrants from Lebanon and Iraq is respectably 46 and 32 per cent. As for the groups with tertiary education, the share is low among the interviewed migrants from Lebanon ( 2 per cent) and from Turkey in the Comcon-data ( 3 per cent). For the Mifare migrants from ex-Yugoslavia (16 per cent), Iraq (14 per cent), and Turkey (20 per cent), the presence of tertiary education is as widespread as among native Danes (15 per cent in the Comcon-data / 18 per cent in the Mifare-data). For the rest of the groups, having tertiary education is more common than it is for natives. The highest shares with tertiary education are found among migrants from the Philippines ( 79 per cent), the US (78 per cent), China (76 per cent), Japan (73 per cent), followed by migrants from Spain (66 per cent), Russia (65 per cent), Great Britain (56 per cent), and Romania (55 per cent). These high education levels are probably a real phenomenon, which underlines that highly educated people have better chances of being mobile (both in terms of economic resources and language skills) and having easier access to destination countries. However, the educational levels also reflect the difficulties in defining what a university/college degree is. In any case, Table 


\begin{tabular}{|c|c|c|c|c|}
\hline & $\begin{array}{l}\text { Lower secondary } \\
\text { education or below }\end{array}$ & $\begin{array}{r}\text { Higher secondary and } \\
\text { post-secondary }\end{array}$ & Tertiary education & $\mathrm{N}$ \\
\hline DNK(Mifare) & 10 & 72 & 18 & 230 \\
\hline POL & 13 & 53 & 34 & 237 \\
\hline ROU & 4 & 41 & 55 & 254 \\
\hline ESP & 11 & 24 & 66 & 302 \\
\hline GBR & 10 & 34 & 56 & 278 \\
\hline TUR & 38 & 42 & 20 & 180 \\
\hline USA & 7 & 15 & 78 & 227 \\
\hline JPN & 13 & 14 & 73 & 232 \\
\hline $\mathrm{CHN}$ & 7 & 17 & 76 & 313 \\
\hline PHL & 5 & 15 & 79 & 219 \\
\hline RUS & 6 & 29 & 65 & 361 \\
\hline DNK(Comcon) & 9 & 76 & 15 & 807 \\
\hline YOU & 22 & 62 & 16 & 116 \\
\hline IRQ & 32 & 55 & 14 & 96 \\
\hline LBN & 46 & 52 & 2 & 52 \\
\hline PAK & 29 & 45 & 26 & 67 \\
\hline TUR & 42 & 55 & 3 & 61 \\
\hline
\end{tabular}

Source: Data collected from the Mifare survey (2018) and Comcon survey (2015).

4.3 again demonstrates a very substantial variation both across and within the groups when it comes to education.

\section{THE DIFFERENT LABOUR MARKET POSITIONS}

Table 4.4 shows the dominant labour market status again based on the Danish register data. As discussed in Chapter 2, entering the labour market is often seen as a driver of broader assimilation. A long line of research has also shown that the labour market status of natives influences attitudes towards the welfare state. One of the standard findings is that the self-employed often are more sceptical about government interventions. The self-employed, however, make up a relatively small share of both natives and migrants; the largest share is 10 per cent of migrants from Turkey in the Mifare-data. Another standard finding is that the unemployed are more positive towards redistribution and unemployment benefits than the employed tend to be. In Table 4.4, the unemployed are calculated as the group having a primary income from unemployment benefits 
Table 4.4 Dominant labour market status based on register information from 2015 (per cent)

\begin{tabular}{lrrrrrr}
\hline & Self-employed & Wage earners & Students & $\begin{array}{r}\text { Unemployed } \\
\text { (registered) }\end{array}$ & Others & N \\
\hline DNK(Mifare) & 3 & 74 & 8 & 6 & 9 & 232 \\
POL & 3 & 71 & 6 & 6 & 14 & 237 \\
ROU & 1 & 65 & 20 & 7 & 7 & 255 \\
ESP & 3 & 48 & 29 & 4 & 15 & 306 \\
GBR & 8 & 67 & 5 & 8 & 12 & 279 \\
TUR & 10 & 41 & 3 & 20 & 26 & 184 \\
USA & 4 & 53 & 20 & 7 & 16 & 229 \\
JPN & 3 & 38 & 19 & 4 & 36 & 233 \\
CHN & 4 & 54 & 19 & 6 & 18 & 316 \\
PHL & 2 & 50 & 7 & 2 & 39 & 220 \\
RUS & 4 & 49 & 13 & 1 & 21 & 365 \\
& & & & & & \\
DNK(Comcon) & 4 & 70 & 14 & 5 & 8 & 807 \\
YOU & 4 & 48 & 9 & 19 & 21 & 119 \\
IRQ & 24 & 21 & 17 & 36 & 97 \\
LBN & 2 & 3 & 40 & 32 & 55 \\
PAK & 1 & 60 & 4 & 11 & 18 & 67 \\
TUR & 2 & 53 & 6 & 12 & 25 & 61 \\
\hline
\end{tabular}

Note: $\quad$ Based on Denmark Statistics classifications.

Source: Data collected from the Mifare survey (2018) and Comcon survey (2015).

or social assistance (in 2015). The share among the interviewed natives is respectively 6 per cent (Mifare-data) and 5 per cent (Comcon-data). Some of the migrant groups have a higher share of people who are unemployed. Especially migrants from Lebanon (40 per cent), Turkey (20 per cent in Mifare-data, 12 per cent in Comcon-data), ex-Yugoslavia (19 per cent), and Iraq (17 per cent) have high unemployment rates. This group of unemployed, receiving benefits, clearly have a self-interest in parts of the welfare state, which following the discussion in Chapters 1 and 2 could influence their welfare attitudes.

The interests and the welfare attitudes of wage earners have proved more difficult to predict though they are net contributors to the Nordic welfare state in this stage of their lives (18- to 60-year-olds, see Chapter 3). Wage earners make up the largest share of the native respondents (74 per cent, Mifare-data, and 70 per cent, Comcon-data). It is also the most common status for all the migrant groups besides the interviewed migrants from Iraq and Lebanon, 
where the share is down to 24 and 23 per cent, respectively. One of the complications with predicting the self-interest of the Nordic wage earners is that many are employed in the public sector. Based on survey information, around one-third of the wage earners answer that they work in the public sector (both in the Mifare- and Comcon-data). On the one hand, this group pay more in taxes than they receive in benefits and services. On the other hand, many of them get their salary from positions within welfare services, for example within teaching, child- and elderly-care, and healthcare.

The previous studies of natives' welfare attitudes have primarily focused on the groups of self-employed, unemployed, and wage earners. However, even in a sample of 18- to 60-year-olds, there is a sizeable group of respondents who are completely outside of the labour market. This is especially the case for migrants. One group is those registered as students. This group makes up respectively 8 and 14 per cent of the native samples. This share is more sizeable among migrants. They make 29 per cent of the interviewed migrants from Spain and around 20 per cent of the migrants from Romania, the US, Japan, China, and Iraq. This overrepresentation in some migrant groups could influence attitudes and values as state-run schools and universities are classic institutions for socialization. It is also an obvious place to get in contact with young adult natives. In other migrant groups, the share is around or below the share found among natives. Finally, in some of the migrant groups, there is a sizeable share who are outside the labour market and at the same time are not students. This group constitutes 39 per cent of the interviewed migrants from the Philippines, 36 per cent of the migrants from Japan, 36 per cent of migrants from Iraq, and around 25 per cent of migrants from Turkey. Part of this group of persons outside the labour market, in their working age, might receive disability pensions or other health-related benefits. However, the registers show that it is not a sizeable share when it comes to migrants. Most of this group of migrants live without public benefits, which means that they rely on the income of the partner/family or occasionally work in the shadow economy. How this group of "others" relates to the welfare state is difficult to theorize or predict. For a start, we simply conclude that there are large differences in labour market status both across natives and migrants and across different migration groups. The exact incomes, the tax payment, and the amount of social benefits received is the topic of the next chapter.

\section{THE DIFFERENT INTENSITY OF RELIGIOUS BELIEFS}

The level of religiosity might also both affect the general process of assimilation and welfare attitudes. As discussed in Chapter 2, migration scholars typically perceive religious belief to be part of a hard-core cultural orientation, which is less affected by destination contexts than more peripheral cultural 
Table 4.5 The intensity of religious beliefs (per cent)

\begin{tabular}{lrrrrr}
\hline & Very religious & Fairly religious & $\begin{array}{r}\text { Not particularly } \\
\text { religious }\end{array}$ & $\begin{array}{r}\text { Not religious } \\
\text { at all }\end{array}$ & N \\
\hline DNK(Mifare) & 0 & 8 & 53 & 38 & 231 \\
POL & 9 & 38 & 38 & 14 & 236 \\
ROU & 4 & 38 & 37 & 21 & 253 \\
ESP & 1 & 7 & 30 & 62 & 303 \\
GBR & 3 & 11 & 35 & 52 & 274 \\
TUR & 17 & 40 & 26 & 17 & 175 \\
USA & 6 & 9 & 53 & 227 \\
JPN & 3 & 19 & 44 & 34 & 233 \\
CHN & 7 & 16 & 25 & 52 & 313 \\
PHL & 6 & 49 & 40 & 5 & 218 \\
RUS & 22 & 49 & 26 & 361 \\
& 2 & & & & \\
DNK(Comcon) & 2 & 12 & 57 & 29 & 808 \\
YOU & 4 & 21 & 43 & 32 & 119 \\
IRQ & 8 & 28 & 50 & 15 & 97 \\
LBN & 11 & 29 & 49 & 10 & 54 \\
PAK & 17 & 56 & 26 & 1 & 67 \\
TUR & 19 & 32 & 43 & 6 & 61 \\
\hline
\end{tabular}

Note: Don't know excluded; small differences in wording in Mifare- and Comcon-data.

Source: Data collected from the Mifare survey (2018) and Comcon survey (2015).

orientations. How religious belief goes together with welfare attitudes is difficult to predict. Among natives, there is little correlation between religious beliefs and welfare attitudes in the Nordic countries. However, if less religious belief is an indicator of more assimilation of general cultural orientation, one could predict a negative association. The Danish destination-country context is Protestant but rather secularized. Few natives indicate that they are "very religious" (in the Mifare- and Comcon-data respectively 0 and 2 per cent) or "fairly religious" (respectively 8 and 12 per cent). See Table 4.5. Most of the migrant groups indicate a higher level of religious belief. The exceptions are migrants from Spain, Great Britain, and the US, who are as secularized as the natives.

Intense religious beliefs are found among migrants with Christian and Muslim backgrounds. Among those with Christian beliefs, the most religious are migrants from Poland, Romania, and the Philippines. Among those with Muslim beliefs, the most religious are migrants from Turkey and Pakistan. Finally, there are groups with moderate-to-higher religiosity than natives. 
These are migrants from Japan, China, Russia, ex-Yugoslavia, Iraq, and Lebanon. Thus, again the data underpin the most-different design logic of the book.

\section{THE DIFFERENT IDENTIFICATION WITH ORIGIN- AND DESTINATION-COUNTRY}

In part the of the literature it is argued that natives' support for the welfare state, especially when it comes to the most redistributive elements, is dependent on a shared national identity (Miller, 1993). To some extent, this is a competing theory to the institutional arguments presented in Chapter 2. The empirical results vary, as always, but one piece of evidence for this suggestion is Singh's (2015) study of how Indian states with more (sub)nationalism developed better education and health service in the post-colonial period (Singh, 2015). The studies that have searched for a micro-level link between natives' national identity and support for the welfare schemes or redistribution are more inconclusive (see Miller \& Ali, 2014, for an overview). The most obvious reason is that surveys are typically fielded in well-established nation-states where close to all responding residents feel a basic sense of national belonging (Bonikowski \& DiMaggio, 2016; Janmaat, 2006; Larsen, 2016a). Thus, what is studied is only the effect from the strength or the character of national identity (e.g. Shayo, 2009; Wright \& Reeskens, 2013), while the importance of national identification in itself is less explored. However, the situation might be different among migrants as one cannot take basic identification with the destination-country for granted (Staerklé, Sidanius, Green, \& Molina, 2010). Therefore, it is relevant to describe the basic national identification of the 14 migrants groups.

In the Mifare-data, we use a question about the feeling of belonging with "Danes" as our primary indicator for national identification. The response categories were "not at all", "weak", "moderate", "close", and "very close". Elaborated analyses including friendships and media consumption indicate that feeling of belonging with Denmark is inversely correlated with the feeling of belonging with the country of origin (not shown). Table 4.6 shows the simple distribution across the ten migrant groups in the Mifare-data; ranged after the share indicating "not at all" and "weak".

Most of the interviewed migrants feel a "moderate" or "close" belonging to Danes. The most common answer is "moderate", which is given by 35 per cent. The second most common is "close", which is given by 25 per cent. Added together, the largest share with, what one could label, dual-cultural national identities is found among the migrants from the Philippines (81 per cent; $42+39)$. Thus, in terms of national identification, the general pattern is dual cultural. It is not a pattern of full assimilation as we expect when it comes 
Table 4.6 Variation in national identification. Feeling of belonging with Danes across Mifare migrant groups (per cent)

\begin{tabular}{lrrrrrrr}
\hline & "Not at all" & "Weak" & "Moderate" & "Close" & "Very close" & Per cent & N \\
\hline ESP & 16 & 32 & 28 & 18 & 7 & 100 & 301 \\
JPN & 21 & 24 & 38 & 14 & 3 & 100 & 232 \\
ROU & 9 & 30 & 35 & 18 & 8 & 100 & 250 \\
POL & 11 & 22 & 35 & 24 & 9 & 100 & 233 \\
CHN & 7 & 23 & 46 & 18 & 7 & 100 & 310 \\
RUS & 9 & 17 & 36 & 20 & 10 & 100 & 342 \\
USA & 5 & 20 & 35 & 29 & 12 & 100 & 227 \\
TUR & 5 & 12 & 41 & 35 & 7 & 100 & 172 \\
GBR & 6 & 10 & 35 & 35 & 15 & 100 & 272 \\
PHL & 3 & 9 & 42 & 39 & 7 & 100 & 218 \\
\hline & 9 & 19 & 35 & 25 & 11 & 100 & 2694 \\
\hline
\end{tabular}

Source: Data collected from the Mifare survey (2018) and Comcon survey (2015).

to welfare attitudes. It is a minority, who feel "very close" belonging with Danes. The overall share is 11 per cent. The share with the most assimilated national identification is found among migrants from Great Britain (15 per cent) and the US (12 per cent). The share is lowest among migrants from Japan (3 per cent). It is also a rare phenomenon to have no feelings of belonging at all. The overall share answering "not at all" is 9 per cent. The share answering "weak" is 19 per cent. Added together, the share answering "not at all" or "weak" is highest among migrants from Spain (48 per cent; $16+32$ ), Japan (45 per cent), and Romania (39 per cent). The share is lowest among migrants from the Philippines (12 per cent), Great Britain (16 per cent), and Turkey (17 per cent).

In the Comcon-data, we do not have a question about the feeling of belonging with Danes (as in the Mifare-data). Instead, we use a question about feeling of belonging with the country of origin. It does not make much of a difference as long as the national identities are one-dimensional, which we also find in elaborated analyses of the Comcon-data (not shown). The response categories were "very strong", "fairly strong", "not strong", and "none". Table 4.7 shows the distribution across the migrant groups; ranked after the share indicating "very strong".

The most common answer is that the interviewed feel "fairly strong" or "not strong" belonging with their country of origin. The overall share is respectively 29 per cent and 42 per cent. We interpret this as dual-cultural in terms of national identity. The largest share with dual-cultural national identification is found among migrants from Pakistan $(81$ per cent, $43+38)$. The lowest share 
Table 4.7 Variation in national identification. Feeling of belonging to the country of origin (Comcon-data, per cent)

\begin{tabular}{lrrrrrr}
\hline & "Very strong" & "Fairly strong" & "Not strong" & "None" & Per cent & N \\
\hline TUR & 25 & 27 & 43 & 6 & 100 & 59 \\
PAK & 18 & 43 & 38 & 1 & 100 & 64 \\
IRAQ & 18 & 28 & 37 & 16 & 100 & 94 \\
YOU & 16 & 34 & 40 & 10 & 100 & 119 \\
LBN & 6 & 14 & 54 & 27 & 100 & 53 \\
& 16 & 29 & 42 & 13 & 100 & 389 \\
\hline
\end{tabular}

Source: Data collected from the Mifare survey (2018) and Comcon survey (2015).

is found among migrants from Iraq ( 65 per cent; $28+37)$. As it was the case in the Mifare-data, it is a minority that has fully assimilated national identification; in the Comcon-data measured as having "none" for feeling of belonging with the country of origin. Overall, 13 per cent answer that they have "no" feeling of belonging towards the country of origin. The largest share with assimilated national identification is found among migrants from Lebanon (27 per cent). The lowest with assimilated national identification is found among migrants from Pakistan (1 per cent). The share with "very strong" feelings of belonging with the origin is a little higher; 16 per cent in the overall Comcon-data. This share is largest among migrants from Turkey (25 per cent) and lowest among migrants from Lebanon (6 per cent).

The overall conclusion is that differences in national identification seem smaller than differences in socio-economic positions. Thus, for all the 14 migrant groups, the typical response is dual cultural identification respectively with Denmark and the country of origin. Thus, in general, the migrants do not assimilate to only identifying with Denmark. This is hardly surprising as we study first-generation migrants. Whether this has an impact on migrants' welfare attitudes will be analysed in the chapters to come.

\section{THE MIXED MIGRATION}

In the public debates, in statistical yearbooks, and even in research-based questionnaires, one often finds the term "immigrants". Sometimes statistics are broken down to EU/non-EU immigrant, Western/non-Western migrants, or refugees/non-refugees. However, a closer look across and within different migrant groups reveals that migration into Northern European countries has become mixed. The chapter has demonstrated sizeable differences even within the group of first-generation migration in their working ages coming from the same country of origin. However, the chapter also found structural patterns 
across the 14 selected groups, which underpin the most-different design logic of the book. Some groups, for example the migrants from Poland, come close to how work-migration within the EU is often imagined. Many of these migrants have only been in Denmark a few years, they have not naturalized, around half of the interviewed are single, most are wage earners and they have not assimilated to the secular beliefs of natives. Other groups, for example the migrants from Lebanon, come close to how forced migration is often imagined. Many from this group have been in Denmark since the civil wars in the 1980s, they have naturalized, their educational level is low, and many have not found their way into the labour market. They are also more religious than natives. However, for most of the 14 groups we interviewed, it is not easy to find one telling label for each group. The migrants from Russia, for example, arrived throughout the period since the end of the cold war, few have naturalized, most are women, most are highly educated, around half are wage earners, most live in mixed couples, and few are religious. As for the interviewed migrants from Pakistan, most are women, most are wage earners, most live in non-ethnic mixed couples, and most have arrived through family unification. Together with the migrants from Turkey, they are the most religious groups. Finally, it goes for the all the 14 migrant groups that they feel a mix of identification with both the country of origin and destination. The overall take-away message from this chapter is that we do indeed have most-different groups. Thereby we maximize potential differences in overall assimilation and assimilation related to welfare attitudes. In the next chapter, we describe the tax payments and the value of social benefits received by both natives and migrants in the working-age population living in Denmark, in order to specify variation in different migrant groups' vested interest in the Danish welfare state. 